\title{
Surface-Bound Cucurbit[8]uril Catenanes on Magnetic Nanoparticles Exhibiting Molecular Recognition ${ }^{* *}$
}

\author{
Xiaohe Ren, ${ }^{\ddagger a}$ Yuchao Wu, ${ }^{\ddagger}{ }^{a}$ David Clarke, ${ }^{a}$ Ji Liu, ${ }^{a}$ Guanglu Wu, ${ }^{a}$ and Oren A. Scherman ${ }^{a} *$
}

\begin{abstract}
Abstratct: We demonstrate the preparation of surfacebound cucurbit[8]uril (CB[8]) catenanes on silica nanoparticles (NPs), where CB[8] was employed as a tethered supramolecular "handcuff" to selectively capture target guest molecules. In this catenane, CB[8] was threaded onto a methyl viologen $\left(\mathrm{MV}^{2+}\right)$ axle and immobilized onto silica NPs. The formation of CB[8] catenanes on NPs were confirmed by $U V$-vis titration experiments and lithographic characterization, demonstrating high density of $C B[8]$ on the silica NPs surface, $0.56 \mathrm{~nm}^{-2}$. This $C B$ [8] catenane system exhibits specific molecular recognition towards certain aromatic molecules such as perylene bis(diimide), naphthol and aromatic amino acids, therefore, can act as a nanoscale molecular receptor for target guests. Furthermore, we also demonstrate its use as an efficient and recyclable nanoplatform for peptide separation. By embedding magnetic NPs inside silica NPs, separation could be achieved by simply applying an external magnetic field. Moreover, the peptides captured by the catenanes could be released by reversible single-electron reduction of $M V^{2+}$. The entire process demonstrated high recoverability.
\end{abstract}

C decades on account of their special mechanically-interlocked molecular architecture. ${ }^{[1-3]}$ The relative positions of their components can be controllably changed without breaking the interlocked structure, allowing catenanes to be readily used as molecular machines, ${ }^{[4,5]}$ switches, ${ }^{[6-8]}$ sensors ${ }^{[9,10]}$ and rotors. ${ }^{[4,11]}$ Macrocyclic host molecules such as crown ethers and cyclodextrins (CDs) are of interest in the preparation of catenanes, on account of their intrinsic cyclic structure and host-guest complexation capability. ${ }^{[2,3,12]}$ Catenanes based on crown ethers were extensively investigated, mainly prepared by template-directed

\footnotetext{
** X. Ren thanks the CSC Cambridge Scholarship for financial support and Dr. Ziyi Yu for template preparation. Y. Wu is financially supported by the EP/L504920/1, J. Liu by the Marie Curie FP7 SASSYPOL ITN (607602) programme, and G. Wu by the Leverhulme Trust.
}

* $\left[{ }^{a}\right]$ X. Ren, ${ }^{\ddagger}$ Y. Wu, ${ }^{\ddagger}$ Dr. D. Clarke, Dr. J. Liu, Dr. G. Wu, and Prof. O. A. Scherman

Melville Laboratory for Polymer Synthesis

Department of Chemistry, University of Cambridge

Lensfield Road, Cambridge, CB2 1EW, UK

Fax: +44 (0)1223 334866; E-mail: oas23@cam.ac.uk

$[\stackrel{\dagger}{\dagger}]$ These authors contributed equally to this work.

Supporting information for this article is available on the WWW under or from the author. synthesis. $^{[2,13]} \mathrm{CD}$ was also studied in the preparation of catenanes on account of its improved binding behavior. ${ }^{[3,14-17]}$ However, crown ether and CD host complexation are both limited to relatively low affinity towards certain guest molecules $\left(K_{a} \leq 10^{5} \mathrm{M}^{-1}\right){ }^{[18,19]}$ Cucurbit[n]urils $(\mathrm{CB}[\mathrm{n}] \mathrm{s})$, a family of symmetric barrel-shaped host molecules, which exhibit stronger and selective encapsulation of small guest molecules, emerged as more promising hosts for supramolecular applications ( $K_{a}$ up to $\left.10^{15} \mathrm{M}^{-1}\right){ }^{[19-24]}$ Cucurbit[8]uril (CB[8]), a larger member of the $\mathrm{CB}$ family possessing a larger cavity volume of $479 \AA^{3}$, can simultaneously encapsulate two guest molecules to form a dynamic yet stable heteroternary complex. ${ }^{[20,25,26]}$ Owing to its excellent host-guest properties, $\mathrm{CB}[8]$ has been utilized as a versatile receptor and building block for various supramolecular architectures and systems. ${ }^{[12,19,21-24]}$ Catenanes containing $\mathrm{CB}[\mathrm{n}]$ were explored by $\operatorname{Kim}^{[27,28]}$ and others, ${ }^{[29]}$ but research has mainly focused on $\mathrm{CB}[6]-$ based catenanes. Few investigations have been conducted on $\mathrm{CB}[8]$-based catenanes despite its unique host-guest properties to simultaneously bind two guests in its cavity. ${ }^{[12,30]}$

Catenanes have been mainly studied in solution, however, to fully develop their potential practical applications, they must be interfaced with the macroscopic world. ${ }^{[3,31]}$ In recent years, effort has been made to attach catenanes on

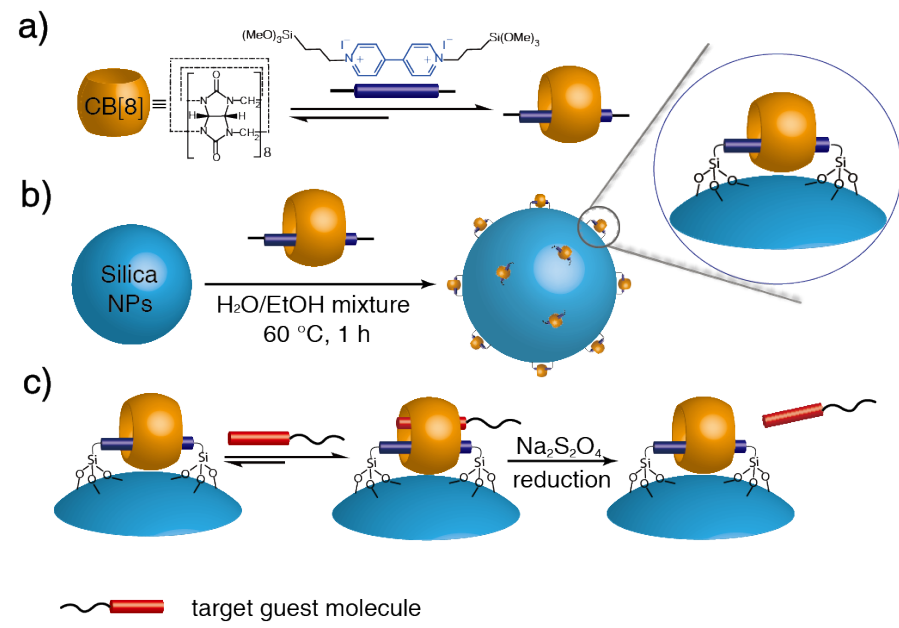

Figure 1 a) Complexation between $\mathrm{CB}[8]$ and $\mathrm{MV}$-silane. b) Surface-bound CB[8] catenanes on silica NPs (CBC-NPs) obtained by immobilizing MV-silane@CB[8] inclusion complexes onto silica NPs. c) Capture and release of a target guest by CBCNPs. 
solid surfaces such as gold and glass to achieve this objective. ${ }^{[6,32,33]}$ We reported the preparation of $\mathrm{CB}[8]$-based interlocked structures immobilized on gold surfaces. ${ }^{[12]}$ Little attention, however, has been paid to the attachment of catenanes on nanoparticles (NPs) ${ }^{[7,16]}$ in spite of their superb properties of large surface area and highly tunable physical and chemical characteristics. ${ }^{[3,34]}$ Herein, for the first time, we demonstrate the preparation of surface-bound $\mathrm{CB}[8]$ catenanes on silica NPs, where $\mathrm{CB}[8]$ is employed as a supramolecular "handcuff" to selectively capture target guests, as shown in Figure 1. This CB[8] catenane system can act as a nanoscale molecular receptor for target guests on account of the specific molecular recognition of the $\mathrm{MV}^{2+} @ \mathrm{CB}[8]$ inclusion complex on silica NPs towards various second guest molecules, including perylene bis(diimide), naphthol and aromatic amino acids, such as tryptophan, ${ }^{[35-37]}$ phenylalanine ${ }^{[36,38]}$ and tyrosine, ${ }^{[36]}$ with the $K_{a}$ of $10^{3}-10^{5} \mathrm{M}^{-1} \cdot{ }^{[36]}$ As a result, this supramolecular system can also act as a highly effective and recyclable nanoplatform for the separation and purification of peptides. The silica NPs can be endowed with magnetism by incorporating superparamagnetic iron oxide into its core, providing an easy and straightforward magnetic separation method.

1,1'-bis[3-(trimethoxysilyl)propyl]-4,4'-bipyridine (MV-silane) was chosen as the first guest molecule to immobilize CB[8] onto silica NPs. The complexation of MV-silane and $\mathrm{CB}[8]$ was investigated by ${ }^{1} \mathrm{H}$ NMR spectroscopy and isothermal titration calorimetry (ITC), see ESI Figures S3 and S4. It exhibited strong 1:1 binding towards $\mathrm{CB}$ [8], with an association constant $K_{a}$ of $3.25 \times 10^{5} \mathrm{M}^{-1}$. The surface-bound $\mathrm{CB}[8]$ catenanes on silica NPs (hereafter referred to as "CBC-NPs") were prepared by immobilizing MV-silane@CB[8] inclusion complexes onto silica NPs. The reaction was conducted in a mixture of water and ethanol $(3: 2 v / v)$ at $60{ }^{\circ} \mathrm{C}$ for $1 \mathrm{~h}$. In the meantime, control NPs were prepared using the same reaction conditions, except in absence of $\mathrm{CB}$ [8]. The average hydrodynamic diameter $\left(D_{h}\right)$ and $\zeta$-potential of CBC-NPs obtained from dynamic light scattering (DLS) were $337 \mathrm{~nm}$ and $35.5 \mathrm{mV}$, respectively (ESI, Table S1 and Figure S5). TEM images of all the NPs show homogeneous size (ESI, Figure S6) and could be well dispersed in water.

To confirm the formation of catenanes on silica NPs and quantify the amount of $\mathrm{CB}[8]$ incorporated into the $\mathrm{CBC}$ NPs, UV-vis titration of substituted perylene bis(diimide) (PDi) was conducted as illustrated in Figure 2a. PDi was employed on account of its good binding affinity towards the $\mathrm{MV}^{2+} @ \mathrm{CB}[8]$ complex. ${ }^{[39,40]}$ The addition of CBC-NPs into PDi solution induced the formation of $\mathrm{CB}[8] / \mathrm{PDi} / \mathrm{MV}$ silane ternary complexes on the silica NPs, leaving the uncoordinated PDi molecules in the solution, which were then separated and quantified. The same procedure was repeated for the control NPs, whereas no PDi molecule was bound. As shown in Figure $2 b$, the absorption of PDi solution showed little change after mixing with the control NPs. In comparison, its absorption decreased linearly with an increasing amount of CBC-NPs added, from 0.165 to 0.074 , which confirms the formation of the catenanes on the silica NPs. The mass fraction of $\mathrm{CB}[8]$ was calculated to be $11.65 \mu \mathrm{g} / \mathrm{mg}$ and the density of $\mathrm{CB}[8]$ on the silica NPs surface was $0.56 \mathrm{~nm}^{-2}$ (more details are shown in ESI).

Lithography was also examined where microscale patterns of a second guest molecule (naphthol-silane) ${ }^{[41]}$ were prepared on a glass surface as illustrated in Figure 3a. The patterned surfaces were immersed in aqueous suspensions of fluorescent rhodamine B (RhB)-labelled CBC-NPs and control NPs, respectively. After extensive washing, patterned surfaces were observed under a fluorescence microscope. As shown in Figures $3 b$ and $3 c$, the fluorescent CBC-NPs aligned in a patterned manner on account of the complexation between the $\mathrm{CB}[8]$ catenane on the CBC-NP surface and naphthol-silane on the glass substrate. In comparison, the fluorescent control NPs could not be observed as they were all washed away (ESI, Figure S8).
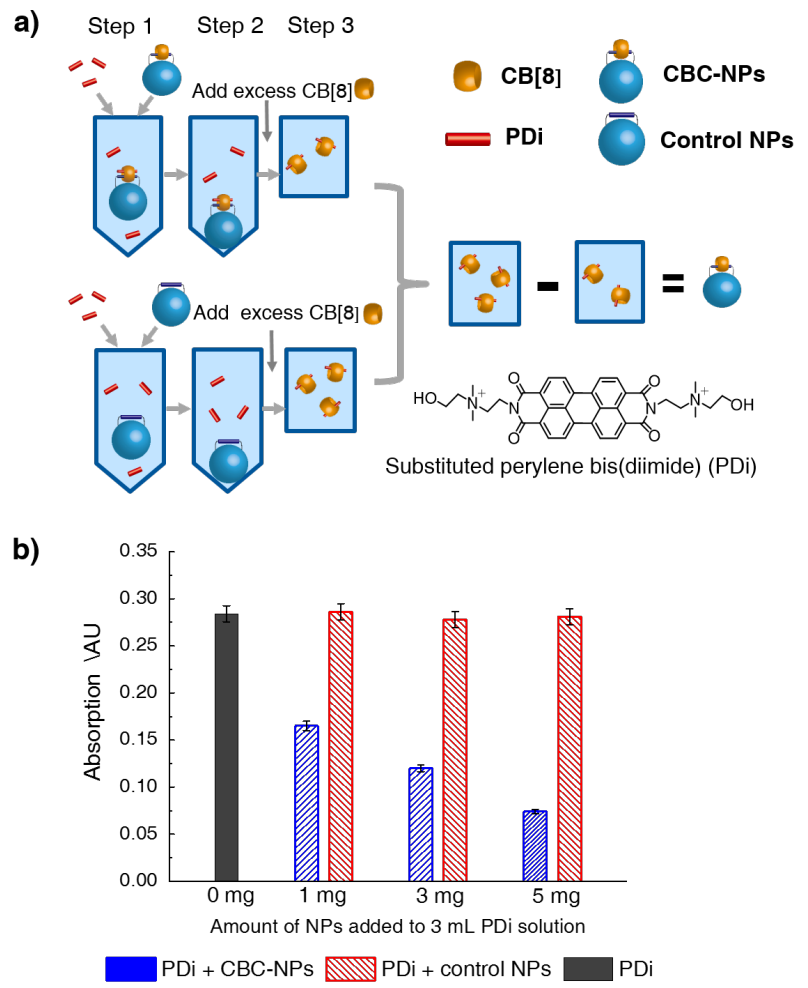

Figure 2 a) Schematic illustration of the UV-vis titration experiment between PDi and CBC-NPs. The addition of CBC-NPs into PDi solution induced the formation of $\mathrm{CB}[8] / \mathrm{PDi} / \mathrm{MV}$-silane ternary complexes on the silica NPs. After centrifuging and removing the sediments, the uncoordinated PDi molecules were left in the solution and quantified. Upon addition of excess CB [8], PDi stacks disassembled and formed complexes with $\mathrm{CB}$ [8], giving the maximum absorption. The same procedure was repeated for the control NPs, whereas no PDi molecule was bound. b) PDi UV-vis absorption $(501 \mathrm{~nm})$ after mixing with different NPs with various mass. 0 , 1, 3, $5 \mathrm{mg}$ NPs solid were added to $3 \mathrm{~mL} 16 \mu \mathrm{M}$ PDi solutions. The absorption decreased linearly with the amount of CBC-NPs added, whereas remaining unchanged after mixing with control NPs. 
a)
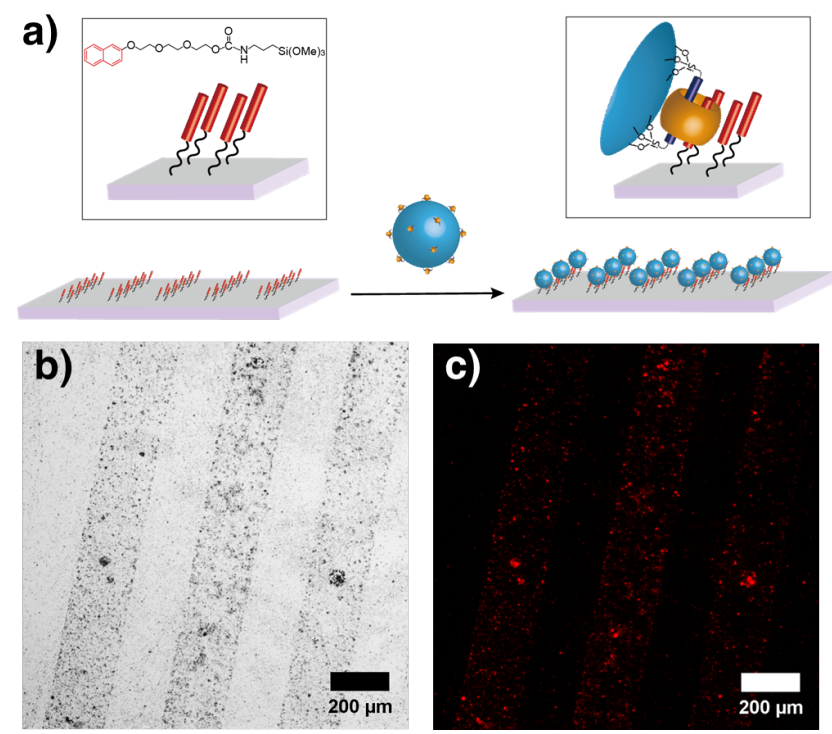

Figure 3 a) Schematic illustration of the lithographic characterization of CBC-NPs. Fluorescence microscope images of RhBlabelled CBC-NPs on the patterned glass, b) bright field, c) dark field. The fluorescent CBC-NPs aligned in a patterned manner due to the complexation between the $\mathrm{CB}[8]$ catenane on the $\mathrm{CBC}-\mathrm{NP}$ surface and naphthol-silane on the glass substrate. In the control experiment using RhB-labelled control NPs (ESI, Figure S8), patterned structure can be barely observed as they were all washed away.

The molecular recognition capability of the $\mathrm{MV}^{2+} @ \mathrm{CB}[8]$ inclusion complexes within the $\mathrm{CB}[8]$ catenane system making it promising to act as a nanoscale molecular receptor for various target guest molecules. Also, as $\mathrm{MV}^{2+} @ \mathrm{CB}[8]$ inclusion complexes exhibit strong binding towards some aromatic amino acids such as tryptophan, ${ }^{[35-37]}$ phenylalanine ${ }^{[36,38]}$ and tyrosine, ${ }^{[36]}$ the selective capture and separation of target peptides containing such residues from peptide mixtures with our $\mathrm{CB}$ [8] catenane system was investigated. In addition, the silica core of CBC-NPs were incorporated with superparamagnetic iron oxide NPs, providing a much easier and more effective way to separate peptides by simply applying an external magnetic field after complexation. The magnetic silica NPs (MNPs) were prepared by the reaction of iron oxide NP ferrofluids and tetraethyl orthosilicate in a 2-propanol/water mixture (TEM images shown in ESI, Figure S10). Surface-bound $\mathrm{CB}[8]$ catenanes on magnetic silica NPs (CBC-MNPs) were prepared by a similar method as CBC-NPs. The TEM image clearly shows the incorporation of iron oxide NPs into the silica NPs (Figure 4a). The CBC-MNPs exhibited strong magnetic responsiveness. As shown in Figure $4 \mathrm{~b}$, the cloudy solution turned to clear within 20 min with almost all CBC-MNPs attracted and accumulated in the corner by a magnet. To investigate the efficiency of peptide separation using CBC-MNPs, model peptide sequences KKKGGGF (F), KKKGGGW (W) and KKKGGG (G) (molecular structures are shown in Figure 5) were synthesized and explored, as illustrated in Figure 5. Peptides $\mathbf{F}$ and $\mathbf{W}$ contain Phe and Trp residues, respectively, and can be recognized by CBC-MNPs. Peptides $\mathbf{G}$ was prepared as a control peptide. The UV absorption of peptide solutions before and after mixing with CBC-MNPs were measured by high-performance liquid chromatography (HPLC). After mixing with CBC-MNPs, the absorptions of $\mathbf{F}$ and $\mathbf{W}$ solutions at both 20 and $40 \mu \mathrm{M}$ decreased significantly, while remaining unchanged for solutions of $\mathbf{G}$, indicating efficient peptide separation by CBC-MNPs (Figure 4 and ESI, Figure S15). The concentration decreased $60 \%$ and $30 \%$ for 20 and $40 \mu \mathrm{M}$ solution, respectivelly, as caculated. The decrease of concentration for both solutions of $\mathbf{F}$ and $\mathbf{W}$ at both 20 and $40 \mu \mathrm{M}$ were similar, around $12 \mu \mathrm{M}$ as calculated, which indicates good reproducibility (ESI, Table S3). The peptide separation efficiency, which is the absorption of peptides per gram CBC-MNPs, was estimated to be 12.5 and $12.2 \mu \mathrm{mol} / \mathrm{g}$ for $\mathbf{F}$ and $\mathbf{W}$, respectively. In addition, the peptides complexed with $\mathrm{MV}^{2+} @ \mathrm{CB}[8]$ on CBC-MNPs can be easily released upon one-electron reduction of $\mathrm{MV}^{2+}$ to its radical cation $\left(\mathrm{MV}^{\cdot+}\right)$ by sodium dithionite $\left(\mathrm{Na}_{2} \mathrm{~S}_{2} \mathrm{O}_{4}\right)$ under nitrogen, ${ }^{[12]}$ exhibiting high release efficiency (up to $11.6 \mu \mathrm{g} / \mathrm{mol}$ ). Moreover, CBC-MNPs can be recovered by the oxidation of $\mathrm{MV}^{+}$to $\mathrm{MV}^{2+}$, simply by purging the
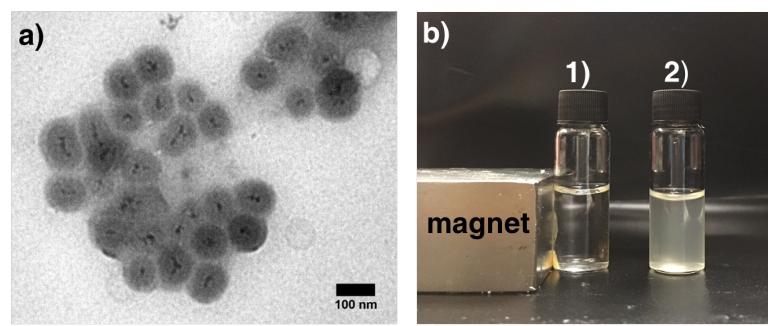

c)

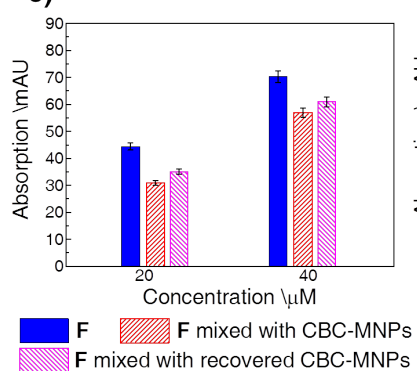

d)

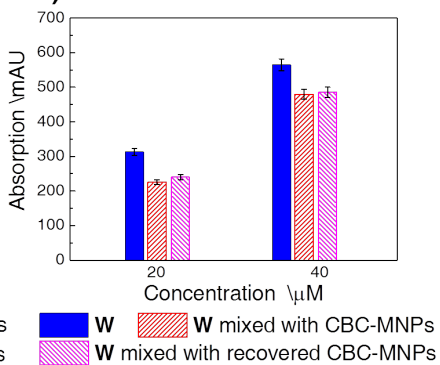

Figure 4 a) TEM image of CBC-MNPs. b) Picture of CBC-MNPs suspensions before (2) and after (1) separation by a magnet. After separating by a magnet for $20 \mathrm{~min}$, the cloudy suspension of CBC-MNPs turned to clear, with most of CBC-MNPs attracted and settled by the magnet. HPLC UV absorption of solutions of c) $\mathbf{F}$ and d) $\mathbf{W}$ at $20 \mu \mathrm{M}$ and $40 \mu \mathrm{M}$ before and after mixing with CBCMNPs. $1.5 \mathrm{~mL}$ peptide solutions in acidic mobile phase $(95 \mathrm{vol} \%$ water, $4.9 \mathrm{vol} \%$ acetonitrile and 0.1 vol\% trifluoroacetic acid) were mixed with $1.5 \mathrm{mg}$ CBC-MNPs. The decrease of concentration for both solutions of $\mathbf{F}$ and $\mathbf{W}$ at 20 and $40 \mu \mathrm{M}$ were similar, around 12 $\mu \mathrm{M}$ according to calculation. While remaining unchanged for solutions of $\mathbf{G}$ (ESI, Figure S15). After recycling of the CBC-MNPs, a subsequent separation cycle showed almost no loss in the separation efficiency, suggesting good recoverability. 


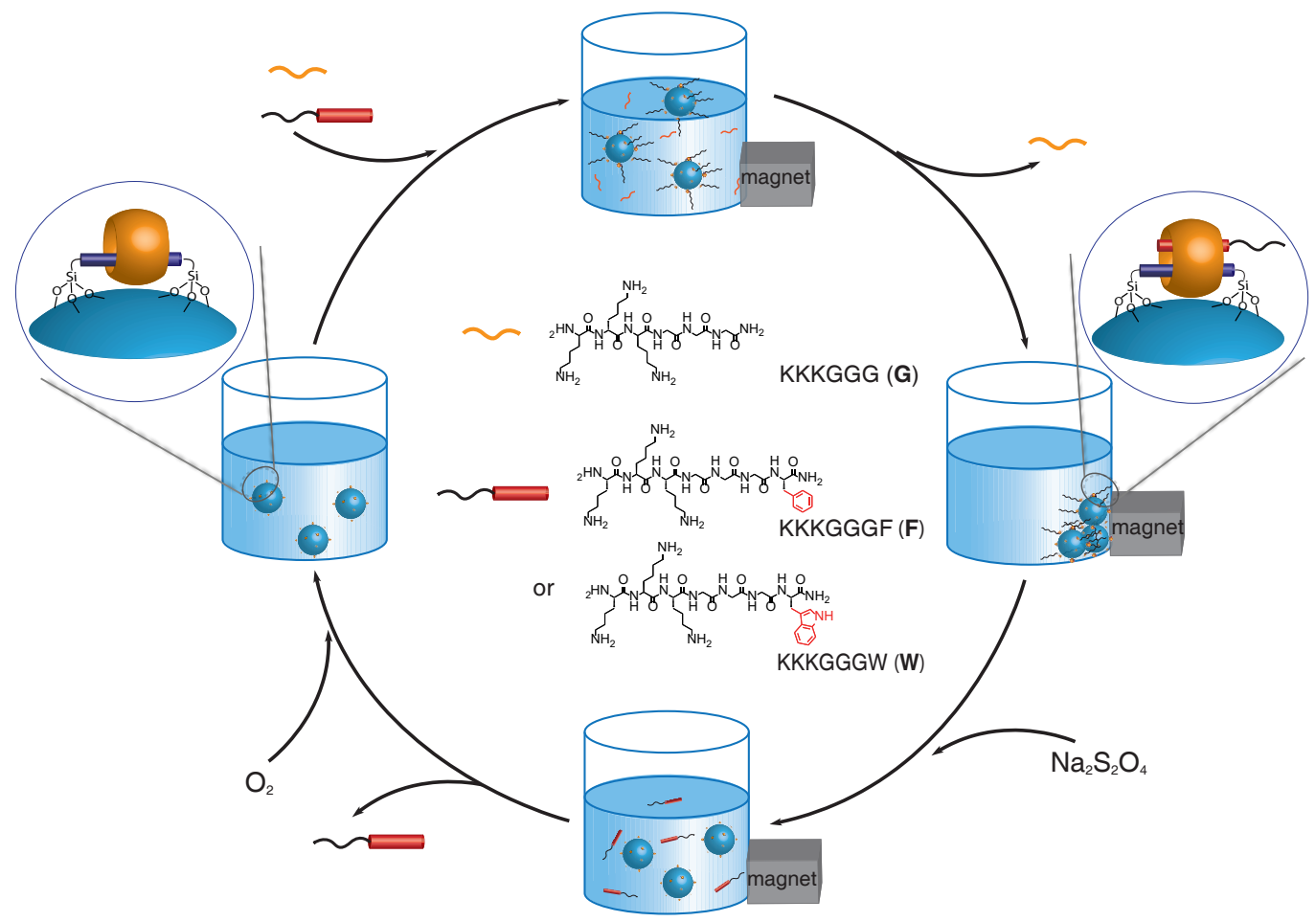

Figure 5 Schematic illustration of the peptide separation using CBC-MNPs and molecular structures of peptides $\mathbf{G}, \mathbf{F}$ and $\mathbf{W}$. After the addition of CBC-MNPs into a peptide mixture, peptides with recognizable residues such as Phe and Trp (i.e. F and W) would complex with CBC-MNPs and sediment upon an external magnetic field. Peptides without recognizable residues such as $\mathbf{G}$, wound remain in the solution and be separated. The complexed peptides $\mathbf{F}$ and $\mathbf{W c a n}$ be released upon one-electron reduction of $\mathrm{MV}^{2+}$ using $\mathrm{Na}_{2} \mathrm{~S}_{2} \mathrm{O}_{4}$ and CBC-MNPs can be reused after the oxidation of $\mathrm{MV}^{\cdot+}$.

solution with oxygen for $1 \mathrm{~min}$. A subsequent separation cycle showed almost no loss in the separation efficiency, up to $11.1 \mu \mathrm{mol} / \mathrm{g}$, suggesting good recoverability (More details shown in ESI, Table S3 and S4)

In conclusion, we have described the preparation of surface-bound CB[8] catenanes on silica NPs. The formation of catenanes on silica NPs was confirmed by UV-vis titration experiments and lithographic characterization. The $\mathrm{CB}[8]$ catenane system acts as a nanoscale molecular receptor for certain aromatic molecules such as PDi, naphthol and aromatic amino acids. We further demonstrated a simple and efficient peptide separation approach using surfacebound $\mathrm{CB}[8]$ catenanes on magnetic NPs, whereby the target peptides could be selectively captured and separated from a peptide mixture and released by the single-electron reduction of $\mathrm{MV}^{2+}$. Moreover, the $\mathrm{CB}[8]$ catenane NPs can be readily recycled after use. The introduction of $\mathrm{CB}[8]$ catenane structures onto NPs allows for single molecule recognition on a micromolar scale, providing potential opportunities in biological sensing and separation.

\section{References}

[1] T. Lu, L. Zhang, G. W. Gokel, A. E. Kaifer, J. Am. Chem. Soc. 1993, $115,2542-2543$.
[2] G. Gil-Ramírez, D. A. Leigh, A. J. Stephens, Angew. Chem. Int. Ed. 2015, 54, 6110-6150.

[3] E. Coronado, P. Gaviña, S. Tatay, Chem. Soc. Rev. 2009, 38, 1674 1689.

[4] J.-P. Sauvage, Acc. Chem. Res. 1998, 31, 611-619.

[5] J.-P. Collin, C. Dietrich-Buchecker, P. Gaviña, M. C. JimenezMolero, J.-P. Sauvage, Acc. Chem. Res. 2001, 34, 477-487.

[6] C. P. Collier, G. Mattersteig, E. W. Wong, Y. Luo, K. Beverly, J. Sampaio, F. M. Raymo, J. F. Stoddart, J. R. Heath, Science 2000, 289, 1172-1175.

[7] R. Klajn, L. Fang, A. Coskun, M. A. Olson, P. J. Wesson, J. F. Stoddart, B. A. Grzybowski, J. Am. Chem. Soc. 2009, 131, 4233-4235.

[8] W.-Q. Deng, A. H. Flood, J. F. Stoddart, W. A. Goddard, J. Am. Chem. Soc. 2005, 127, 15994-15995.

[9] Y. Nakatani, Y. Furusho, E. Yashima, Angew. Chem. Int. Ed. 2010, 49, 5463-5467.

[10] A. Caballero, F. Zapata, N. G. White, P. J. Costa, V. Félix, P. D. Beer, Angew. Chem. 2012, 124, 1912-1916.

[11] S. Bonnet, J.-P. Collin, M. Koizumi, P. Mobian, J.-P. Sauvage, Adv. Mater. 2006, 18, 1239-1250.

[12] C. Hu, Y. Lan, F. Tian, K. R. West, O. A. Scherman, Langmuir 2014, 30, 10926-10932.

[13] B. Mohr, J.-P. Sauvage, R. H. Grubbs, M. Weck, Angew. Chem. 1997, 109, 1365-1367.

[14] D. Armspach, P. R. Ashton, C. P. Moore, N. Spencer, J. F. Stoddart, T. J. Wear, D. J. Williams, Angew. Chem. Int. Ed. 1993, 32, 854-858.

[15] J. Li, P. Nowak, H. Fanlo-Virgós, S. Otto, Chem. Sci. 2014, 5, 49684974. 
[16] Y.-L. Zhao, Y. Chen, M. Wang, Y. Liu, Org. lett. 2006, 8, 12671270.

[17] T. Hoshino, M. Miyauchi, Y. Kawaguchi, H. Yamaguchi, A. Harada, J. Am. Chem. Soc. 2000, 122, 9876-9877.

[18] M. V. Rekharsky, Y. Inoue, Chem. Rev. 1998, 98, 1875-1918.

[19] D. Das, O. A. Scherman, Isr. J. Chem. 2011, 51, 537-550.

[20] J. Kim, I.-S. Jung, S.-Y. Kim, E. Lee, J.-K. Kang, S. Sakamoto, K. Yamaguchi, K. Kim, J. Am. Chem. Soc. 2000, 122, 540-541.

[21] E. A. Appel, J. del Barrio, X. J. Loh, O. A. Scherman, Chem. Soc. Rev. 2012, 41, 6195-6214

[22] Y. Lan, Y. Wu, A. Karas, O. A. Scherman, Angew. Chem. Int. Ed. 2014, 53, 2166-2169.

[23] J. Liu, C. S. Y. Tan, Y. Lan, O. A. Scherman, Macromol. Chem. Physic. 2016, 217, 319-332.

[24] Y. Wu, Y. Lan, J. Liu, O. A. Scherman, Nanoscale 2015, 7, 1341613419.

[25] A. Day, A. P. Arnold, R. J. Blanch, B. Snushall, J. Org. Chem. 2001, 66, 8094-8100.

[26] E. A. Appel, F. Biedermann, U. Rauwald, S. T. Jones, J. M. Zayed, O. A. Scherman, J. Am. Chem. Soc. 2010, 132, 14251-14260.

[27] D. Whang, K.-M. Park, J. Heo, P. Ashton, K. Kim, J. Am. Chem. Soc. 1998, 120, 4899-4900.

[28] K.-M. Park, S.-Y. Kim, J. Heo, D. Whang, S. Sakamoto, K. Yamaguchi, K. Kim, J. Am. Chem. Soc. 2002, 124, 2140-2147.

[29] A. I. Day, X. Xiao, Y.-Q. Zhang, Q.-J. Zhu, S.-F. Xue, Z. Tao, J. Inclusion Phenom. Mol. Recognit. Chem. 2011, 71, 281-286.
[30] Y. H. Ko, K. Kim, J.-K. Kang, H. Chun, J. W. Lee, S. Sakamoto, K. Yamaguchi, J. C. Fettinger, K. Kim, J. Am. Chem. Soc. 2004, 126, 1932-1933.

[31] C. Hamers, O. Kocian, F. M. Raymo, J. F. Stoddart, Adv. Mat. 1998, 10, 1366-1369.

[32] N. H. Evans, H. Rahman, A. V. Leontiev, N. D. Greenham, G. A. Orlowski, Q. Zeng, R. M. Jacobs, C. J. Serpell, N. L. Kilah, J. J. Davis, et al., Chem. Sci. 2012, 3, 1080-1089.

[33] C. Nadai, C. Whelan, C. Perollier, G. Clarkson, D. Leigh, R. Caudano, P. Rudolf, Surf. Sci. 2000, 454, 112-117.

[34] M.-C. Daniel, D. Astruc, Chem. Rev. 2004, 104, 293-346.

[35] F. Tian, M. Cziferszky, D. Jiao, K. Wahlstrom, J. Geng, O. A. Scherman, Langmuir 2010, 27, 1387-1390.

[36] M. E. Bush, N. D. Bouley, A. R. Urbach, J. Am. Chem. Soc. 2005, $127,14511-14517$

[37] J. J. Reczek, A. A. Kennedy, B. T. Halbert, A. R. Urbach, J. Am.Chem. Soc. 2009, 131, 2408-2415.

[38] S. Sonzini, S. T. Ryan, O. A. Scherman, Chem. Commun. 2013, 49, 8779-8781.

[39] F. Biedermann, E. Elmalem, I. Ghosh, W. M. Nau, O. A. Scherman, Angew. Chem. Int. Ed. 2012, 124, 7859-7863.

[40] S. T. Ryan, J. Del Barrio, I. Ghosh, F. Biedermann, A. I. Lazar, Y. Lan, R. J. Coulston, W. M. Nau, O. A. Scherman, J. Am. Chem.Soc. 2014, 136, 9053-9060.

[41] U. Rauwald, O. A. Scherman, Angew. Chem. Int. Ed. 2008, 47, 3950-3953. 